\title{
Lessons learned from recommissioning a public office building
}

\author{
Yuyang Miao ${ }^{1}$, Chenggang Liu ${ }^{1, \mathrm{a}}$ and Xinjiang Huang ${ }^{1}$ \\ ${ }^{1}$ School of Environment Science and Engineering, Suzhou University of Science and Technology, 215009 SuZhou, China
}

\begin{abstract}
Energy consumption of HVAC system play a big role on the whole building energy usage. Recommissioning on HVAC system can improve build comfort and its performance. Taking the recommissioning of public office as an example, the issue of the energy consumption of HVAC system was found, control scheme of chilled and hot water system and AHUs was optimized, the new energy saving control scheme was determined, and the actual energy consumption was analysed. The result show that recommissioning for the public office building achieved obviously effect, and the rate of energy saving is $18 \%, 33 \%$ and $10 \%$ for chilled water, hot water and electricity, respectively.
\end{abstract}

\section{Introduction}

In modern society, along with the rise and great development of the intelligence buildings, the scale of the HVAC system is increasing greatly, and the equipments category and quantity are increasing numerously, and failure arise inevitable ${ }^{[1]}$. Recommissioning in aircondition system is important in improving energy efficiency ${ }^{[2-3]}$, maintaining a comfortable indoor thermal and humidity environment ${ }^{[4-5]}$ and extending the service time of equipment ${ }^{[6-8]}$. The recommissioning of the public office building was taken as an example to display the difference in energy consumption between prerecommissioning and post-recommissioning.

The public office building located in Zhangjiagang consists of two buildings(a building A and a building B), totaling $11,200 \mathrm{~m}^{2}$ of conditioned area. Both buildings consist of 3 stories, a ground floor, and a basement. Building A totals $5,500 \mathrm{~m}^{2}$. The entire basement is the mechanical room for the building and the remaining floors are primarily offices with few meeting room and lounges. The building B totals 5,700 $\mathrm{m}^{2}$. The basement consists of storage and the remaining floors are primarily meeting rooms with some lounges.

The building $\mathrm{A}$ is served by two large air-handling units (AHUs) located in the basement, AHU-1 and AHU2. Both of these units consist a preheat coil and a cooling coil. The schematic of AHUs was shown in the Figure 1. The discharge air from both units enters a common duct and is then supplied to terminal VAV reheat boxes for the entire building. The building $\mathrm{A}$ has two constant speed chilled water and two constant speed hot water pumps, which are located in the basement. Each chilled water and hot water pump supplies one of the AHUs. The building A has 2 general exhaust fan for the toilets. The entire HVAC system for this building is controlled pneumatically.

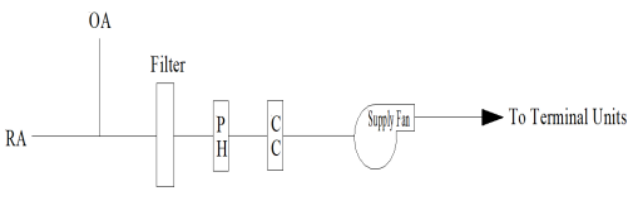

Figure 1. Schematic of AHU-1,-2

The building B is served by five AHUs, AHU-3, AHU-4, AHU-5, AHU-6, and AHU-7. All AHUs are preheat and then cooling with terminal VAV reheat boxes and direct digital control (DDC). While the VAV boxes have local pneumatic controls. AHU-3 serves a boardroom on the 1st and 2nd floor. AHU-4 serves the west part of the building and AHU-5 serves the east part of the building. AHU-6 serves the basement and ground floors of the central part of the building's north-east. AHU-7 serves the rear part of the building's north and also serves the entire 4th floor of the north. The building $\mathrm{B}$ has one chilled water pump and one hot water pump, both of which are equipped with a VFD and DDC control. The building has 4 general exhaust fans, two of them serve toilets and others serve storage.

\section{Recommissioning measures}

At first, all of the AHUs were measured for airflows and temperatures and compared with EMCS readings and design data. Then the chilled water control valve of AHU-3 in the building B was found stuck in the fully open position and was replaced.

And it was found that the chilled water pump's VFD in the building $B$ would not maintain a continuous speed above $55 \mathrm{~Hz}$ in order to maintain the building's differential pressure (DP). Above this speed, the VFD would continually ramp the motor down and then back up.

\footnotetext{
a Corresponding author: cliu1977@163.com
} 
VAV boxes were inspected for malfunctioning parts, which included the fan, reheat valve, damper, and damper actuator. The result shows that the boxes has many problems of leakage stuck and failure, for example, there were 12 reheat valve stuck and 6 damper leaked in the basement and ground floor, these kind of problems have also been found on the remaining floor.All of the fault components were calibrated and replaced as necessary.

All exhaust fans were checked and measured for airflow rate. And it turns out air intake of the building through AHUs was balanced.

Then the building air balance was performed. See the Table 1 for the result. For the building A the design inlet airflow is $15,900 \mathrm{~m}^{3} / \mathrm{h}$ and the exhaust air flow is $16,830 \mathrm{~m}^{3} / \mathrm{h}$. The measured inlet airflow was $13,400 \mathrm{~m}^{3} / \mathrm{h}$ and the measured exhaust flow was $19,800 \mathrm{~m}^{3} / \mathrm{h}$. The building operating static pressure was negative as designed.And for the building $\mathrm{B}$ the design inlet airflow is $23,450 \mathrm{~m}^{3} / \mathrm{h}$ and the exhaust air flow is $23,550 \mathrm{~m}^{3} / \mathrm{h}$. The measured inlet airflow was $20,740 \mathrm{~m}^{3} / \mathrm{h}$ and the measured exhaust flow was $21,700 \mathrm{~m}^{3} / \mathrm{h}$. The building operating static pressure was negative as designed. In order to combat the problem, the coils and outside inlet was cleaned, the fan belts was replaced and the filters was changed.

Table 1. Building air balance

\begin{tabular}{|c|c|c|c|c|}
\hline \multirow{2}{*}{ Building } & \multicolumn{2}{|c|}{ Air Intake $\left(\mathbf{m}^{3} / \mathbf{h}\right)$} & \multicolumn{2}{c|}{ Exhaust $\left(\mathbf{m}^{3} / \mathbf{h}\right)$} \\
\cline { 2 - 5 } & design & measured & design & measured \\
\hline A & 15900 & 13400 & 16830 & 19800 \\
\hline B & 23450 & 20740 & 23500 & 21700 \\
\hline
\end{tabular}

\section{HVAC control system}

\subsection{Existing control scheme}

\subsubsection{Building A existing control scheme}

The chilled water and hot water pump existing control scheme in building $\mathrm{A}$ is that all pumps are constants speed with no control. There is only a manual local on/off switch.

And the building chilled water valve is modulated to maintain the building DP at its set point. The building hot water valve is modulated to maintain the building return temperature set point.

The existing control scheme of AHU-1 and AHU-2 is the preheat control valve and cooling control valve are couple controlled to maintain the discharge temperature at its set point.
Otherwise, the fan VFD is varied to maintain the discharge static pressure at its set point.

The issues of the existing control scheme in the building $\mathrm{A}$ is that the system could be upgraded to DDC control.

\subsubsection{Building B existing control scheme}

The chilled water and hot water pump existing control scheme is that the chilled water VFD is varied to maintain the building chilled water differential pressure (DP) at its setpoint of $275 \mathrm{kpa}$ or to maintain the chilled water flow rate of $110 \mathrm{~m}^{3} / \mathrm{h}$, whichever is satisfied first.

And the hot water VFD is varied to maintain the building hot water differential pressure (DP) at its setpoint of $170 \mathrm{kpa}$ or to maintain the hot water flow rate of $90 \mathrm{~m}^{3} / \mathrm{h}$, whichever satisfied first.

The existing control scheme of AHU-4, AHU-5 AHU-6 AHU-7 is the chilled water control valve of these AHUs is modulated to maintain the discharge air temperature at the constant set point of $16^{\circ} \mathrm{C}$. The supply fan speed is varied to maintain the end static pressure at the constant set point of $0.3,0.38,0.5$, and $0.4 \mathrm{kpa}$ for AHU-4, AHU-5, AHU-6 and AHU-7, respectively.

The preheat control valve is modulated to maintain the preheat temperature at the set point of $16^{\circ} \mathrm{C}$. And the hot water circulate pump for each AHU will run when the outside air temperature is lower than $13^{\circ} \mathrm{C}$ and will be off when the temperature is greater than or equal to $16^{\circ} \mathrm{C}$.

In addition, for freeze protection, when the preheat temperature is lower than $39^{\circ} \mathrm{F}$, the AHU will shut off and the preheat and cooling control valves will fully open.

the control scheme of AHU-3 is the cooling and reheat control valves are couple controlled to maintain the boardroom space temperature of $22^{\circ} \mathrm{C}$. The cooling control valve is modulated to maintain the relative humidity ( $\mathrm{RH})$ at its set point of $50 \%$, as well. Either both set points could be met or one would be met and the other would be lower than its set point.

Through the above description of existing control scheme in building B, there are some measures as below should be taken to save energy.

(1) The chilled water and hot water pumps is not necessary to maintain a constant DP set point of $275 \mathrm{kpa}$ for chilled water and $170 \mathrm{kpa}$ for hot water. The DP set points should be reset based on the cooling and heating loads.

(2) Both pumps are not necessary to maintain a chilled water flow rate of $110 \mathrm{~m}^{3} / \mathrm{h}$ and a hot water flow rate of $90 \mathrm{~m}^{3} / \mathrm{h}$ with a design flow rate of $105 \mathrm{~m}^{3} / \mathrm{h}$ and $25 \mathrm{~m}^{3} / \mathrm{h}$, respectively.

(3) The hot water circulate pumps for AHU-4, AHU5, AHU-6 and AHU-7 should be turned on when needed and have a dead band to avoid the pump cycle on/off.

(4) It is not necessary to turn these hot water circulate pumps at $16^{\circ} \mathrm{C}$. The pumps should turn on when they are needed.

(5) The discharge temperature set points and static pressure set points of AHU-4, AHU-5, AHU-6 and 
AHU-7 need to be reset based on cooling and heating load.

\subsection{New control scheme}

The control scheme of building A was not altered, but some recommendation could be taken when the control system is upgrade from pneumatic to DDC control. For example, a magnetic flow meter needs to be installed on the chilled water and hot water systems, the fan speed can be varied to maintain the discharge static pressure at a setpoint, the set point is calculated according to outside air temperature, and the preheat and cooling control valves will then be modulated to maintain a discharge temperature set point. The set point is calculated according to outside air temperature.

Then the control scheme of building B is modified as follow:

The chilled water and hot water pumps speed control scheme was controlled to maintain the chilled water and hot water DP at its set point of a constant value. The new DP set point was reset according to outside air temperature. See Table 2 below for details.

Table 2. Chilled water and hot water DP set point

\begin{tabular}{|c|c|c|}
\hline Toa $\left({ }^{\circ} \mathbf{C}\right)$ & CHW DPsp (kpa) & HW DPsp (kpa) \\
\hline 10 & 55 & 85 \\
\hline 15 & 70 & 70 \\
\hline 20 & 85 & 55 \\
\hline 25 & 105 & 40 \\
\hline
\end{tabular}

And both chilled water and hot water VFDs are varied to maintain the building chilled water and hot water differential pressure (DP) at their setpoints.

The discharge air temperature set point of AHU-4, AHU-5 AHU-6 AHU-7 was reset based on outside air temperature as Table 3 shown below.

Table 3. Discharge air temperature set point

\begin{tabular}{|c|c|}
\hline Toa $\left({ }^{\circ} \mathbf{C}\right)$ & Tdis $\left({ }^{\circ} \mathbf{C}\right)$ \\
\hline 10 & 20 \\
\hline 15 & 19 \\
\hline 20 & 18 \\
\hline 25 & 17 \\
\hline 30 & 16 \\
\hline
\end{tabular}

The static pressure set point was reset according to outside air temperature as Table 4 shown below.

Table 4. Static pressure set point

\begin{tabular}{|c|c|c|c|c|}
\hline Toa $\left({ }^{\circ} \mathrm{C}\right)$ & $\begin{array}{c}\text { AHU-4 } \\
(\mathrm{kpa})\end{array}$ & $\begin{array}{c}\text { AHU-5 } \\
(\mathrm{kpa})\end{array}$ & $\begin{array}{c}\text { AHU-6 } \\
(\mathrm{kpa})\end{array}$ & $\begin{array}{c}\text { AHU-7 } \\
(\mathrm{kpa})\end{array}$ \\
\hline
\end{tabular}

\begin{tabular}{|l|l|l|l|l|}
\hline 10 & 0.13 & 0.13 & 0.20 & 0.15 \\
\hline 15 & 0.15 & 0.15 & 0.23 & 0.18 \\
\hline 20 & 0.18 & 0.18 & 0.23 & 0.20 \\
\hline 25 & 0.20 & 0.20 & 0.28 & 0.25 \\
\hline 30 & 0.25 & 0.25 & 0.33 & 0.30 \\
\hline
\end{tabular}

The preheat temperature setpoint for the preheat valve is $16^{\circ} \mathrm{C}$, the same as before.

The hot water circulate pumps will be on when mix air temperature before the preheat coil is less than $8^{\circ} \mathrm{C}$ and will be turned off when the temperature is $10^{\circ} \mathrm{C}$ and above.

The control scheme of AHU-3 has been changed to the cooling and reheat control valves are controlled to maintain the boardroom space temperature at $23{ }^{\circ} \mathrm{C}$ for cooling and $21^{\circ} \mathrm{C}$ for heating.

Also the cooling valve will modulate to maintain relative humidity at the setpoint of $55 \%$ instead of $50 \%$.

\section{Energy Consumption Analysis}

Since the building A conrtol system has pneumatic which no energy consumption data is available. However, building B owns DDC control system to allow trend data. Therefore, the energy consumption analysis is performed for building $B$ only.And the result was shown in the Figure 2, Figure 3 and Figure 4.

Commissioning activities started on 07/01/2017 and ended on 07/30/2017. All the data comparisons are between pre-RC and post-RC. Pre-RC data, 01/01/2017-06/30/2017, was marked as $\mathrm{x}$. Post-RC data $07 / 31 / 2017$ - $12 / 31 / 2017$, was marked as .

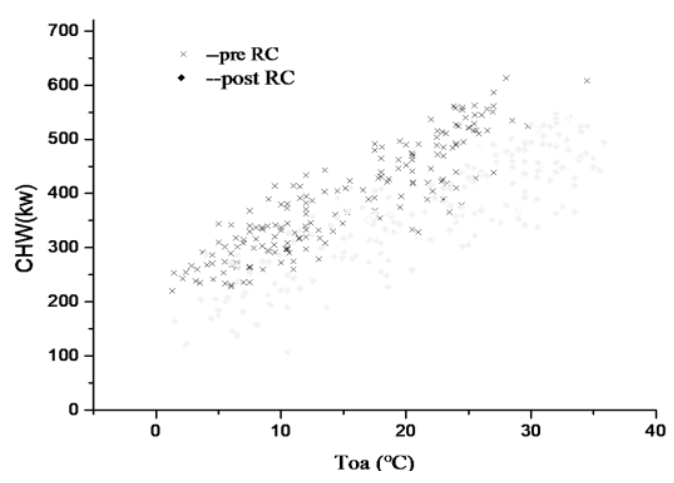

Figure 2. Chilled water consumption 


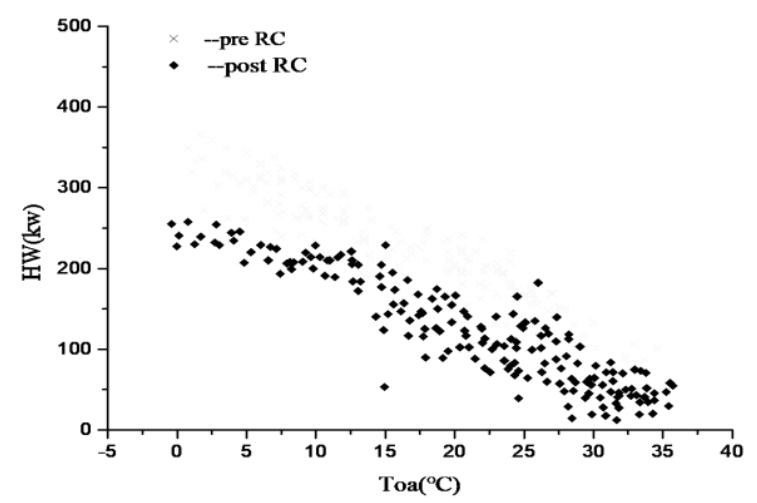

Figure 3. Hot water consumption

(1) From Figure 2, the chilled water consumption was reduced by an average of about $96 \mathrm{kw}$. About $18 \%$ of chilled water saving was achieved.

(2) From Figure 3, the hot water consumption was reduced by an average of about $84 \mathrm{kw}$. About $33 \%$ of hot water saving was achieved.

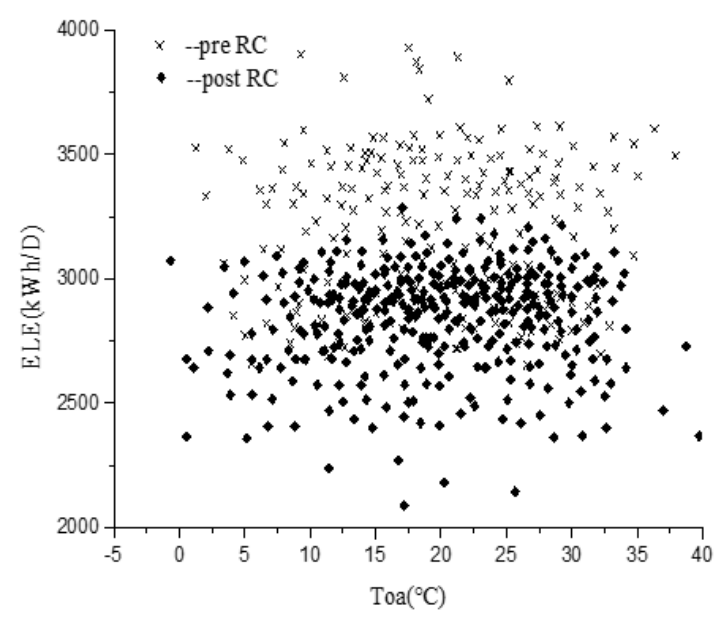

Figure 4. Electricity consumption

(3) From Figure 4, the electricity consumption was reduced by an average of about $400 \mathrm{kWH} /$ day. About $10 \%$ of electricity saving was achieved.

\section{Conclusion}

Through the recommissioning, the fault components of the air condition system in the public office building were replaced, and the control scheme of the system was optimized and improved. And a significant result of energy saving was achieved, the consumption of chilled water, hot water and electricity were reduced by $18 \%$, $33 \%$ and $10 \%$.

\section{References}

1. L. Lan. Fault detection and diagnosis in air-source heat pump air-conditioning system use PCA method. Hunan University,2008..

2. T. Nagota,Y. Shimoda,M. Mizuno. Verification of the energy-saving effect of the district heating and cooling system-Simulation of an electric-driven heat pump system. Energy \& Buildings,2007,40(5).

3. Budaiwi,A. Abdou. HVAC system operational strategies for reduced energy consumption in buildings with intermittent occupancy.The case of mosques. Energy Conversion and Management,2013,73.

4. J. Liu,Y. Liu,L. Yang,L. Hou,M. Wang,J. Liu. Annual energy saving potential for integrated application of phase change envelopes and HVAC in Western China[J]. Procedia Engineering,2017,205.

5. L. Wang, S. Greenberg, J. Fiegel, A. Rubalcava, S. Earni, X. Pang, R. Yin, S. Woodworth, J. Hernandez-Maldonado. Monitoring-based HVAC commissioning of an existing office building for energy efficiency. Applied Energy,2013,102.

6. K. Bruton, P. Raftery, P. O'Donovan, N. Aughney, M. M. Keane, D.T.J. O'Sullivan. Development and alpha testing of a cloud based automated fault detection and diagnosis tool for Air Handling Units. Automation in Construction,2014,39.

7. C. Ren, N. Li, G. Tang. Principles of exergy analysis in HVAC and evaluation of evaporative cooling schemes. Building and Environment, 2002,37

8. C. B. Smith, K. E. Parmenter. Management of Heating and Cooling. Energy Management Principles (Second Edition),2016,125-187. 